\title{
EVALUASI DAN POTENSI PENGOPERASIAN BUS SEKOLAH (STUDI KASUS : BUS HALOKES KOTA MALANG)
}

\author{
Evaluation And Potential Operation Of School Bus \\ (Case Study: Bus Halokes Poor Town)
}

\author{
Tony Prasetyo ${ }^{1}$, Ludfi Djakfar ${ }^{2}$, Sobri Abusini ${ }^{3}$ \\ 1,2,3 Jurusan Teknik Sipil, Fakultas TeknikUniversitas Brawijaya \\ Alamat korespondensi : Jln. MT. Haryono, Malang, Jatim \\ email: tony_ayu@yahoo.co.id
}

\begin{abstract}
Malang is a city with a high population density about 8129 people / km2. Malang city is known as a tourism and educational city. The high population and many activities causes a traffic jam in Malang. To reduce the traffic jam and help students reduce using private motorcycle, Malang goverment provide some free school bus for students. The method used in this research is descriptive quantitative analysis with the description of public transport operational performance analysis and analysis of vehicle operating costs. It also used SWOT method to determine the performance of the school bus, potential, problems and strategies used to develop a school bus. The results showed that operational performance is good with load factor value less than 1 every segment. The travel speed average is $40 \mathrm{~km} / \mathrm{hour}$ about 40 until 60 minutes. The service time is about two times in every morning and afternoon and the waiting time of passengers between 5 to 10 minutes. The results of BOK calculation is Rp145.579,- a day which is subsidized by the government of Malang city. Based on the user's perception of school buses, the most important factors considered are comfort, safety and reliability. Based on SWOT calculations, the development strategy contained in a space that is rapid growth strategy that harnesses the strength and the opportunities.
\end{abstract}

Keyword : School buses, operational performance, BOK, SWOT, development strategy

\begin{abstract}
Abstrak
Kota Malang merupakan kota dengan kepadatan penduduk yang tinggi mencapai 8.129 jiwa/ $\mathrm{km}^{2}$. Selain sebagai kota wisata, kota Malang juga dikenal sebagai kota pendidikan. Tingginya kepadatan penduduk Kota Malang sejalan dengan beragamnya aktifitas yang ada menyebabkan terjadinya kemacetan di Kota Malang. Untuk mengurangi kemacetan dan membantu pelajar mengurangi penggunaan kendraan pribadi, pemerintah Kota Malang menyediakan bus sekolah gratis bagi para pelajar. Penelitian ini bertujuan untuk Evaluasi kinerja bus sekolah menggunakan metode Analisis Deskriptif serta analisis biaya operasional kendaraan serta metode SWOT untuk mengetahui kinerja dan strategi. Hasil penelitian menunjukkan bahwa kinerja operasional kendaraan cukup baik dengan nilai loadfactor kurang dari 1 per segmen dengan kecepatan perjalanan rata-rata $40 \mathrm{~km} / \mathrm{jam}$ dan waktu tempuh 40-60 menit. Waktu pelayanan 2 kali yakni berangkat dan pulang sekolah dengan waktu tunggu penumpang antara 5 sampai 10 menit. Sementara itu hasil perhitungan BOK adalah Rp 145.579,per hari yang disubsidi pemerintah. Berdasarkan persepsi pengguna bus sekolah kenyamanan, keamanan dan keandalan adalah faktor yang dirasa paling penting. Berdasarkan hasil perhitungan SWOT, strategi pegembangan terdapat pada ruang A yaitu rapid growth strategy yakni strategi pertumbuhan cepat dengan memanfaatkan kekuatan dan peluang yang ada.
\end{abstract}

Kata Kunci : Bus sekolah, kinerja operasional, BOK, SWOT, strategi pengembangan

\section{PENDAHULUAN}

Kota Malang merupakan kota dengan kepadatan penduduk cukup tinggi, yaitu 8.129 jiwa/ $\mathrm{km}^{2}$ pada tahun 2011. Padatnya penduduk Kota
Malang akibat urbanisasi, menjadi salah satu penyebab kemacetan. Kota Malang juga memiliki lokasi yang dekat dengan Kota Batu dan lokasi wisata lain di Kabupaten Malang, sehingga sering dijadikan tempat transit oleh para wisatawan. 
Selain sebagai kota wisata, Kota Malang juga dikenal sebagai Kota Pendidikan. Potensi sebagai kota pendidikan tersebut didukung dengan berbagai fasilitas pendidikan yang lengkap mulai dari tingkat dasar hingga perguruan tinggi. Banyaknya fasilitas pendidikan tersebut sejalan dengan tingkat kebutuhan akan alat trasportasi yang dapat mendukung mobiltas siswa untuk menuju ke sekolah masing-masing.

Seiring dengan perkembangan teknologi transportasi saat ini, pengguna kendaraan bermotor semakin meningkat pula. Pengguna kendaraan bermotor tersebut beragam mulai pelajar hingga orang ua. Meningkatnya teknologi transportasi khususnya kendaraan roda 2 , juga mempengaruhi pilihan pelajar SMA maupun SMP untuk memilih kendaraan bermotor tersebut sebagai sarana menuju ke sekolah. Hal ini menjadi permasalahan tersendiri karena di Indonesia ketentuan kendaraan bermotor telah diatur dalam Undang-undang no 22 Tahun 2009 tentang Lalu Lintas dan Angkutan Jalan. Telah dijelaskan pada pasal 288 ayat 2 bahwa setiap orang yang mengemudikan kendaraan bermotor dijalan harus memiliki SIM (Surat Ijin Mengemudi) dimana untuk mendapatkan SIM salah satunya persyaratan usia minimal adalah 17 tahun. Persyaratan tersebut tentu belum bisa dipenuhi oleh pelajar SMA kebawah.

Pilihan pelajar untuk menggunakan kendaraan pribadi juga karena meskipun di Kota Malang terdapat angkutan kota, namun pelayanan yang diberikan masih kurang maskimal. Sebagai penumpang, para pelajar merasa tidak nyaman, harus menunggu lama, bahkan harus berdesakan agar mikrolet dapat mulai jalan. Selain itu, para pelajar juga sering terlambat masuk ke sekolah dikarenakan pengemudi angkot tidak memperdulikan penumpang pelajar.para pelajar kesulitan mendapatkan angkutan umum dikarenakan angkot banyak yang menolak mengangkut pelajar dengan alasan tarifnya lebih murah daripada penumpang umum. Hal inilah yang menyebabkan pelajar beralih ke kendaraan pribadi.

Permasalahan tersebut membuat Pemerintah Kota Malang berinisiatif untuk menyediakan bus sekolah yang membantu pelajar dalam mobilisasi baik berangkat maupun pulang sekolah. Pengadaan bus sekolah ini diharapkan mampu mengurangi penggunaan kendaraan bermotor oleh pelajar SMP maupun SMA. Selain itu juga diharapkan mampu mengurangi kemacetan. Namun pengadaan bus sekolah ini menjadi polemik karena para supir angkutan umum yang tidak setuju dengan adanya bus sekolah ini. Berdasarkan observasi sementara juga para pelajar belum memiliki minat yang besar untuk menggunakan bus sekolah.

Oleh karena itu, dirasa perlu untuk mengkaji kinerja operasional dan potensi bus sekolah Kota Malang agar nantinya dapat membantu meningkatkan pelayanan terhadap pelajar.

Penelitian ini mempunyai beberapa tujuan, antara lain:

- Menganalisis kinerja bus sekolah di Kota Malang

- Menganalisis potensi dan masalah yang ada dalam pengoperasionalan bus sekolah di Kota Malang

- Menganalisis strategi yang tepat untuk pengembangan bus sekolah di Kota Malang.

\section{METODE PENELITIAN}

Pelaksanaan penelitian ini terdiri dari beberapa tahapan. Tahapan-tahapan di dalam studi ini adalah:

- Mengidentifikasi dan merumuskan permasalahan yang akan diteliti berdasarkan pada latar belakang masalah yang telah diuraikan sebelumnya.

- $\quad$ Studi Literatur atau Kajian Pustaka.

- Indentifikasi kinerja operasional us sekolah, biaya operasional kendaraa, potensi masalah serta persepsi penumpang.

- Melakukan pengumpulan data primer dan data skunder di wilayah kajian studi dilakukan dengan wawancara dan menyebarkan kuisioner, serta meminta data pada instansi terkait.

- Data hasil kuisioner yang diperoleh melalui wawancara responden kemudian dianalisa dengan metode Analisa Deskriptif.

- Langkah terakhir adalah menarik kesimpulan sesuai dengan rumusan masalah dari hasil analisa dan pembahasan.

Pada penelitian ini metode analisis yang digunakan adalah Analisis SWOT. Metode ini untuk mengetahui strategi dasar pemecahan masalah yang dapat diterapkan secara kualitatif. Analisis SWOT tersebut akan menjelaskan apakah informasi tersebut berindikasi sesuatu yang akan membantu 
pemerintah mencapai tujuannya atau memberikan indikasi bahwa terdapat rintangan yang harus dihadapi atau diminimalkan untuk memenuhi pemasukan yang diinginkan.

Analisis SWOT dapat digunakan dengan berbagai cara untuk meningkatkan analisis dalam usaha penetapan strategi. Umumnya yang sering digunakan adalah sebagai kerangka / panduan sistematis dalam diskusi untuk membahas kondisi altenatif dasar yang mungkin menjadi pertimbangan pemerintah.

Pendekatan kualitatif matriks SWOT sebagaimana dikembangkan oleh Kearns, (1992) menampilkan delapan kotak, yaitu dua paling atas adalah kotak faktor eksternal (peluang dan tantangan) sedangkan dua kotak sebelah kiri adalah faktor internal (kekuatan dan kelamahan). Empat kotak lainnya merupakan kotak isu-isu strategis yang timbul sebagai hasil titik pertemuan antara faktorfaktor internal dan eksternal.

Data SWOT kualitatif di atas dapat dikembangkan secara kuantitaif melalui perhitungan Analisis SWOT yang dikembangkan oleh Pearce and Robinson (1998) agar diketahui secara pasti posisi organisasi yang sesungguhnya. Perhitungan yang dilakukan melalui tiga tahap, yaitu:

- Melakukan perhitungan skor (a) dan bobot (b) point faktor setta jumlah total perkalian skor dan bobot $(\mathrm{c}=\mathrm{a} \times \mathrm{b}$ ) pada setiap faktor S-WO-T; Menghitung skor

- Masing-masing poin faktor dilakukan secara saling bebas (penilaian terhadap sebuah poin faktor tidak boleh dipengaruhi atau mempengeruhi penilaian terhadap poin faktor lainnya. Pilihan rentang besaran skor sangat menentukan akurasi penilaian namun yang lazim digunakan adalah dari 1 sampai 10, dengan asumsi nilai 1 berarti skor yang paling rendah dan 10 berarti skor yang paling tinggi.

- Masing-masing poin faktor dilaksanakan secara saling ketergantungan. Artinya, penilaian terhadap satu poin faktor adalah dengan membandingkan tingkat kepentingannya dengan poin faktor lainnya. Sehingga formulasi perhitungannya adalah nilai yang telah didapat (rentang nilainya sama dengan banyaknya poin faktor) dibagi dengan banyaknya jumlah poin faktor).
- 2. Melakukan pengurangan antara jumlah total faktor $\mathrm{S}$ dengan $\mathrm{W}$ (d) dan faktor $\mathrm{O}$ dengan $\mathrm{T}$ (e); Perolehan angka $(\mathrm{d}=\mathrm{x})$ selanjutnya menjadi nilai atau titik pada sumbu $X$, sementara perolehan angka $(\mathrm{e}=\mathrm{y})$ selanjutnya menjadi nilai atau titik pada sumbu Y.

- 3. Mencari posisi organisasi yang ditunjukkan oleh titik $(\mathrm{x}, \mathrm{y})$ pada kuadran SWOT.

\section{HASIL DAN PEMBAHASAN}

\section{Geometris Wilayah}

Secara geografis Kota Malang terletak pada koordinat $112^{\circ} 06^{\prime}-112^{\circ} 07^{\prime}$ Bujur Timur dan $7^{\circ} 06^{\prime}$ - $8^{\circ} 02^{\prime}$ Lintang Selatan. Kota Malang terletak di Provinsi Jawa Timur dengan jumlah penduduk 857.891 jiwa ini (2014). Luas wilayah kota Malang adalah $110,06 \mathrm{~km}^{2}$. Malang merupakan kota terbesar kedua di Jawa Timur setelah Surabaya dengan batas wilayah sebagai berikut:

- Utara : Kecamatan Singosari dan Kec. Karangploso Kabupaten Malang

- Timur : Kecamatan Pakis dan Kecamatan Tumpang Kabupaten Malang

- Selatan : Kecamatan Tajinan dan Kecamatan Pakisaji Kabupaten Malang

- Barat : Kecamatan Wagir dan Kecamatan Dau Kabupaten Malang

Berikut ini pembagian segmen bus halokes (Gambar 1, Gambar 2, dan Gambar 3)

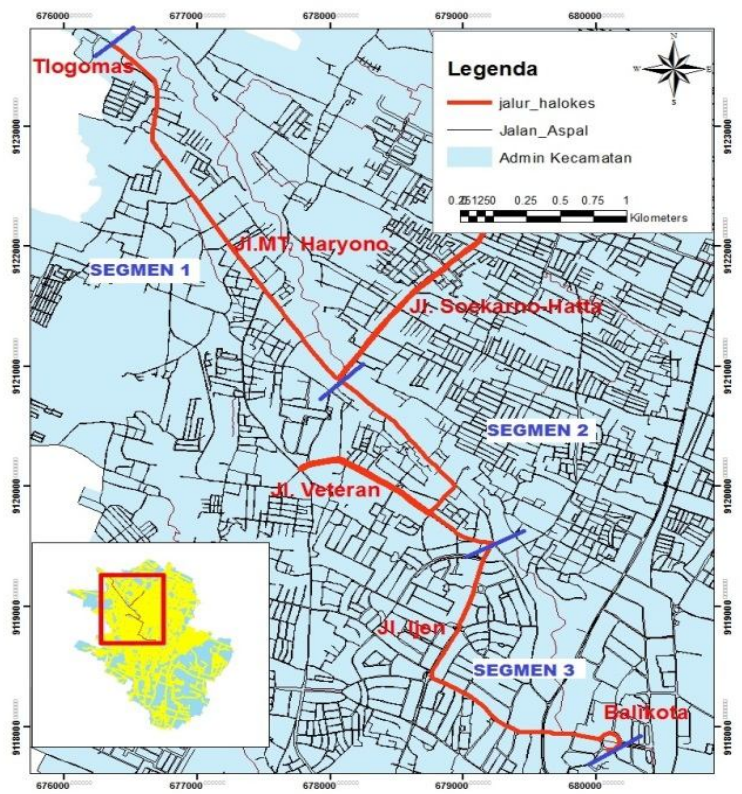

\section{PETA RUTE BUS HALOKES 1}

Gambar 1. Peta Rute Dan Segmen Bus 1 


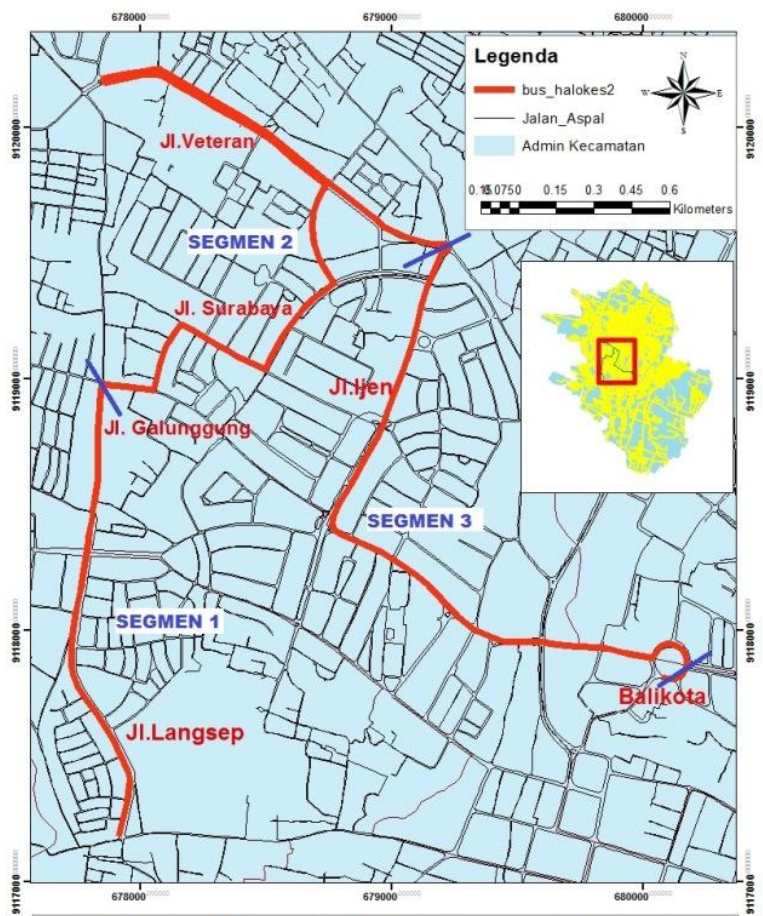

PETA RUTE BUS HALOKES 2

Gambar 2. Peta Rute Dan Segmen Bus 2

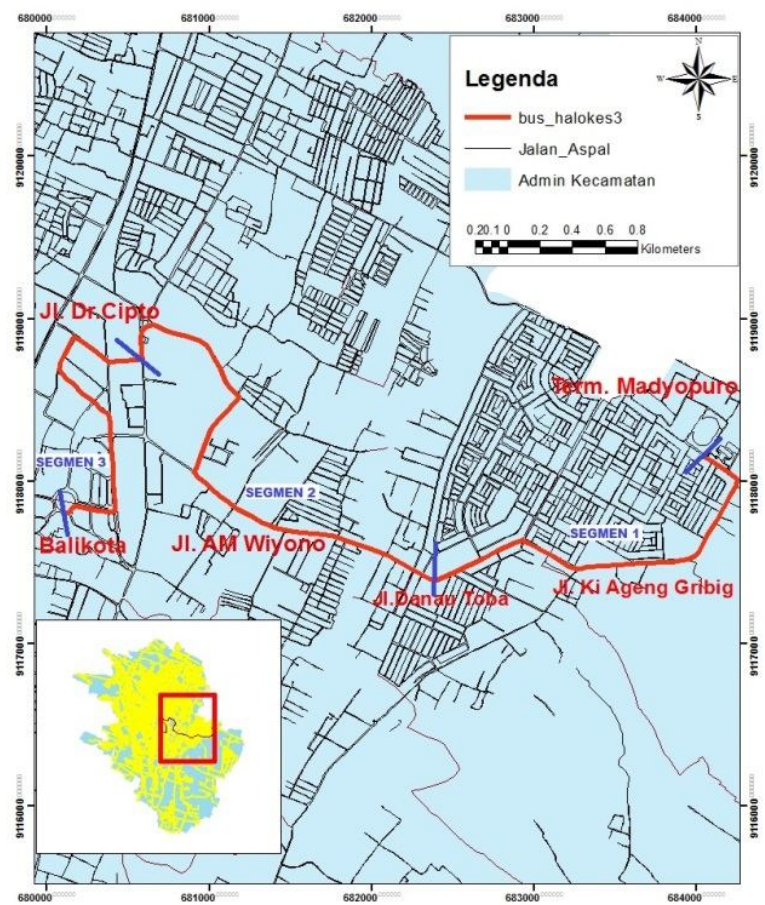

PETA RUTE BUS HALOKES 3

Gambar 3. Peta Rute Dan Segmen Bus 3

\section{Analisis Kinerja Operasional Bus Sekolah}

Pada Tabel 1, Tabel 2 dan Tabel 3 dapat dilihat bahwa Nilai load factor kurang dari 1 untuk semua rute dan segmen, menunjukkan bahwa kapasitas bus sekolah masih memenuhi bagi pangguna bus sekolah. Sementara itu, nilai tertinggi load factor terdapat pada segmen 3 pada tiap rute. Hal ini dikarenakan segmen 3 merupakan segmen pemberhentian terakhir untuk bus berangkat sekolah serta segmen paling awal untuk bus pulang sekolah. Alasan ini pula yang bisa menyebabkan segmen 1 pada masing- masing rute menjadi segmen yang paling kecil nilai load factor nya.

Tabel 1. Load Factor Bus Halokes 1

\begin{tabular}{llccc}
\hline $\begin{array}{c}\text { Waktu } \\
\text { Survei }\end{array}$ & $\begin{array}{c}\text { Rute } \\
\text { Bus }\end{array}$ & $\begin{array}{c}\text { Jumlah } \\
\text { Penumpang }\end{array}$ & Kapasitas & $\begin{array}{c}\text { Load } \\
\text { Factor }\end{array}$ \\
\hline Pagi & $\begin{array}{l}\text { Segmen } \\
1\end{array}$ & 14 & 40 & $\mathbf{0 , 3 5}$ \\
& $\begin{array}{l}\text { Segmen } \\
2\end{array}$ & 28 & 40 & $\mathbf{0 , 7}$ \\
& $\begin{array}{l}\text { Segmen } \\
3\end{array}$ & 30 & 40 & $\mathbf{0 , 7 5}$ \\
\hline Siang & $\begin{array}{l}\text { Segmen } \\
1\end{array}$ & 10 & 40 & $\mathbf{0 , 2 5}$ \\
& $\begin{array}{l}\text { Segmen } \\
2\end{array}$ & 19 & 40 & $\mathbf{0 , 4 7 5}$ \\
& Segmen \\
& 3 & & & \\
\hline
\end{tabular}

Tabel 2. Load Factor Bus Halokes 2

\begin{tabular}{llccc}
\hline $\begin{array}{c}\text { Waktu } \\
\text { Survei }\end{array}$ & $\begin{array}{c}\text { Rute } \\
\text { Bus }\end{array}$ & $\begin{array}{c}\text { Jumlah } \\
\text { Penumpang }\end{array}$ & Kapasitas & $\begin{array}{c}\text { Load } \\
\text { Factor }\end{array}$ \\
\hline Pagi & $\begin{array}{l}\text { Segmen } \\
1\end{array}$ & 11 & 40 & $\mathbf{0 , 2 7 5}$ \\
& $\begin{array}{l}\text { Segmen } \\
\text { 2 }\end{array}$ & 19 & 40 & $\mathbf{0 , 4 7 5}$ \\
& $\begin{array}{l}\text { Segmen } \\
\text { 3 }\end{array}$ & 22 & 40 & $\mathbf{0 , 5 5}$ \\
\hline Siang & $\begin{array}{l}\text { Segmen } \\
\text { 1 }\end{array}$ & 7 & 40 & $\mathbf{0 , 1 7 5}$ \\
& $\begin{array}{l}\text { Segmen } \\
2\end{array}$ & 16 & 40 & $\mathbf{0 , 3 7 5}$ \\
& $\begin{array}{l}\text { Segmen } \\
3\end{array}$ & 15 & 40 & $\mathbf{0 , 4}$ \\
\hline
\end{tabular}

Tabel 3. Load Factor Bus Halokes 3

\begin{tabular}{llccc}
\hline $\begin{array}{c}\text { Waktu } \\
\text { Survei }\end{array}$ & $\begin{array}{c}\text { Rute } \\
\text { Bus }\end{array}$ & $\begin{array}{c}\text { Jumlah } \\
\text { Penumpang }\end{array}$ & Kapasitas & $\begin{array}{c}\text { Load } \\
\text { Factor }\end{array}$ \\
\hline Pagi & $\begin{array}{l}\text { Segmen } \\
1\end{array}$ & 13 & 40 & $\mathbf{0 , 3 2 5}$ \\
& $\begin{array}{l}\text { Segmen } \\
2\end{array}$ & 18 & 40 & $\mathbf{0 , 4 5}$ \\
& $\begin{array}{l}\text { Segmen } \\
\text { 3 }\end{array}$ & 29 & 40 & $\mathbf{0 , 7 2 5}$ \\
\hline Siang & $\begin{array}{l}\text { Segmen } \\
1\end{array}$ & 7 & 40 & $\mathbf{0 , 2 5}$ \\
& $\begin{array}{l}\text { Segmen } \\
2\end{array}$ & 16 & 40 & $\mathbf{0 , 4 2 5}$ \\
& $\begin{array}{l}\text { Segmen } \\
3\end{array}$ & 15 & 40 & $\mathbf{0 , 5 2 5}$ \\
\hline
\end{tabular}


Rata-rata kecepatan perjalanan bus halokes Kota Malang adalah $40 \mathrm{~km} / \mathrm{jam}$. Kecepatan kendaraan tersebut dapat dikatakan ideal bagi penumpang bus sekolah karena penumpang tidak perlu menunggu waktu yang lama untuk menuju sekolah masing-masing dibandingkan dengan menggunakan angkutan umum dengan hasil pada (Tabel 4)

Tabel 4. Kecepatan Perjalanan

\begin{tabular}{ccccc} 
Bus & Segmen & $\begin{array}{c}\text { Jarak } \\
(\mathbf{k m})\end{array}$ & $\begin{array}{c}\text { Waktu } \\
(\mathbf{m e n i t})\end{array}$ & $\begin{array}{c}\text { Kecepatan } \\
(\mathbf{k m} / \mathbf{j a m})\end{array}$ \\
\hline Bus & 1 & & 12 & 40 \\
halokes 1 & & 4,25 & & 40 \\
& 2 & 3,5 & 10 & 40 \\
\hline Bus & 3 & 3 & 8 & 40 \\
halokes 2 & 1 & & 5 & 40 \\
& 2 & 4,8 & 15 & 40 \\
\hline Bus & 3 & 3 & 10 & 40 \\
halokes 3 & 1 & & 8 & 40 \\
& 2 & 2,5 & 15 & 40 \\
\hline
\end{tabular}

waktu tempuh bus halokes hampir sama pada siang hari yakni 40 sampai 45 menit. Namun untuk pagi hari, waktu tempuh bus halokes 1 memiliki nilai yang paling tinggi. hal ini bisa disebabkan karena bus halokes 1 memiliki jumlah sekolah yang paling banyak untuk dikunjungi. Seperti pada Tabel 5.

Tabel 5. Waktu Tempuh Bus Halokes

\begin{tabular}{|c|c|c|c|c|}
\hline Waktu & Bus & $\begin{array}{c}\text { Awal } \\
\text { (WIB) }\end{array}$ & $\begin{array}{l}\text { Akhir } \\
\text { (WIB) }\end{array}$ & $\begin{array}{l}\text { Waktu } \\
\text { tempuh }\end{array}$ \\
\hline \multirow[t]{3}{*}{ Pagi } & $\begin{array}{l}\text { bus } \\
\text { halokes } 1\end{array}$ & 05.30 & 06.30 & 60 menit \\
\hline & $\begin{array}{l}\text { halokes } 2 \\
\text { bus }\end{array}$ & 06.05 & 06.45 & 40 menit \\
\hline & halokes 3 & 06.00 & 06.40 & 40 menit \\
\hline \multirow[t]{3}{*}{ Siang } & $\begin{array}{l}\text { bus } \\
\text { halokes } 1 \\
\text { bus }\end{array}$ & 14.15 & 14.55 & 40 menit \\
\hline & $\begin{array}{l}\text { halokes } 2 \\
\text { bus }\end{array}$ & 14.05 & 14.50 & 45 menit \\
\hline & halokes 3 & 14.15 & 13.00 & 45 menit \\
\hline
\end{tabular}

Waktu pelayanan bus halokes Kota Malang terdiri dari dua waktu yakni pagi dan siang. Waktu paling pagi dimulai pada jam 05.30 WIB dan diakiri paling lambat pada jam 06.45 WIB yakni pada jam masuk sekolah. Sementara itu, untuk waktu siang dimulai pada jam 14.05 WIB diakhiri pada jam 14.55 yakni pada saat penumpang sudah diantar ke tujuan sesuai rute. rata-rata waktu tunggu penumpang di halte adalah 5-10 menit.

\section{Analisis Biaya Operasional Kendaraan (BOK)}

Biaya Operasional Kendaraan (BOK) dihitung berdasarkan jenis kendaraan yaitu bus sekolah yang merupakan kendaraan berat (HV). Pada perhitungan kali ini digunakan asumsi dasar berupa rata-rata jarak tempuh yang dilalui oleh kendaraan, sehingga dapat diketahui komponen setiap BOK dalam satuan rupiah per hari.

Tabel 6. Perhitungan BOK

\begin{tabular}{|c|c|}
\hline Komponen Biaya & HV \\
\hline $\begin{array}{ll}\text { Biaya } & \text { Penyusutan } \\
\text { (Rp/hari) } & \end{array}$ & 54 \\
\hline Biaya Modal & 4.627 \\
\hline Biaya Asuransi & 8717 \\
\hline $\begin{array}{l}\text { Harga Bahan Bakar } \\
\text { (Rp/hari) }\end{array}$ & 100.000 \\
\hline Harga Ban (Rp/hari) & 5.358 \\
\hline Harga pelumas (Rp/hari) & 2.560 \\
\hline $\begin{array}{l}\text { Total biaya tetap + tidak } \\
\text { tetap }(\mathrm{Rp} / \mathrm{hari})\end{array}$ & 121.316 \\
\hline $\begin{array}{l}\text { Biaya lain-lain }(20 \% \\
\text { biaya tetap + tidak tetap })\end{array}$ & 24.263 \\
\hline Total BOK (Rp/Hari) & 145.579 \\
\hline
\end{tabular}

Dari hasil perhitungan dapat diketahui bahwa komponen biaya operasional kendaraan menghasilkan total biaya sebesar Rp 145.579,- per hari dengan beban paling tinggi berada pada biaya bahan bakar. Biaya secara keseluruhan ditanggung oleh pemerintah Kota Malang. Subsidi dari pemerintah Kota Malang mencakup semua biaya operasional termasuk gaji pengemudi dan asisten pengemudi bus per bulan sebesar Rp 1.600.000,untuk pengemudi bus dan Rp 1.400.000,- untuk asisten pengemudi bus. Karena seluruh biaya pengeluaran ditanggung oleh pemerintah, maka para pelajar tidak perlu lagi membayar untuk bisa menaiki bus sekolah Kota Malang.

\section{Persepsi penumpang}

Sebagian besar, penumpang bus halokes menganggap variabel keandalan, keamanan, kenyamanan adalah variabel yang sangat penting 
yang mempengaruhi pilihan pelajar untuk menggunakan bus halokes. Dari hasil survei, 30\% penumpang memilih keandalan sebagai variabel yang paling penting diantara variabel yang lain. Dua variabel berikutnya yang dianggap sangat penting adalah kenyamanan dan keamanan. Sementara itu, variabel yang dirasa cukup penting bagi penumpang adalah harga yang murah dan waktu tempuh perjalanan bus. Hal ini dikarenakan beberapa penumpang tidak mempermasalahkan harga yang harus dibayar ketika akan manaiki bus sekolah (oper angkutan) dan juga adanya bus sekolah ini secara keseluruhan dibiayai oleh pemerintah.

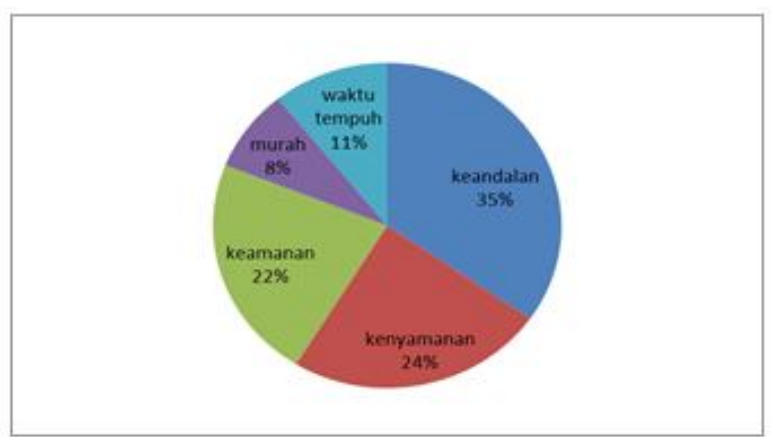

Gambar 4. Persepsi Penumpang Bus

\section{Analisis SWOT}

Berdasarkan hasil survei mengenai potensi dan masalah pada bus halokes, dapat dikategorikan kekuatan, kelemahan, peluang dan ancaman sebagai berikut:

\section{Kekuatan (strength)}

- Terdapat sarana prasarana pendukung seperi AC dan wifi sehingga bus sekolah bersih, aman dan nyaman

- Jam berangkat dan waktu tempuh yang cepat mengurangi keterlambatan siswa

- Memudahkan pelajar dalam berangkat dan pulang sekolah

\section{Kelemahan (weakness)}

- $\quad$ Rute yang pendek dan sedikit

- Bus hanya beroperasi pada jam-jam tertentu

- Waktu bus untuk berhenti di halte hanya sebentar

- $\quad$ Kapasitas tempat duduk kurang sehingga jika saat ramai, pelajar harus berdiri karena jumlah armada bus yang sedikit
- Pelajar harus menungggu kedatangan bus baik pada saat berangkat maupun pulang sekolah dan bus tidak parkir tepat didepan sekolah

\section{Peluang (Opportunity)}

- Adanya dukungan pemerintah dalam hal pembiayaan

- Mengurangi penggunaan kendaraan pribadi

- Membiasakan tertib, karena pelajar hanya dapat menaiki kendaraan di halte yang telah di tentukan dan pulang tepat waktu

- Mengurangi kemacetan pada ruas jalan yang dilalui rute bus sekolah

\section{Ancaman (treaths)}

- $\quad$ Adanya konflik dengan pihak angkutan umum kota apabila terjadi penambahan pada rute bus

- Adanya kebijakan pembatasan jumlah rute bus

- Belum adanya lajur khusus bus sekolah

- Data SWOT kualitatif di atas dapat dikembangkan secara kuantitaif melalui perhitungan Analisis SWOT yang dikembangkan oleh Pearce and Robinson (1998) agar diketahui secara pasti posisi organisasi yang sesungguhnya.

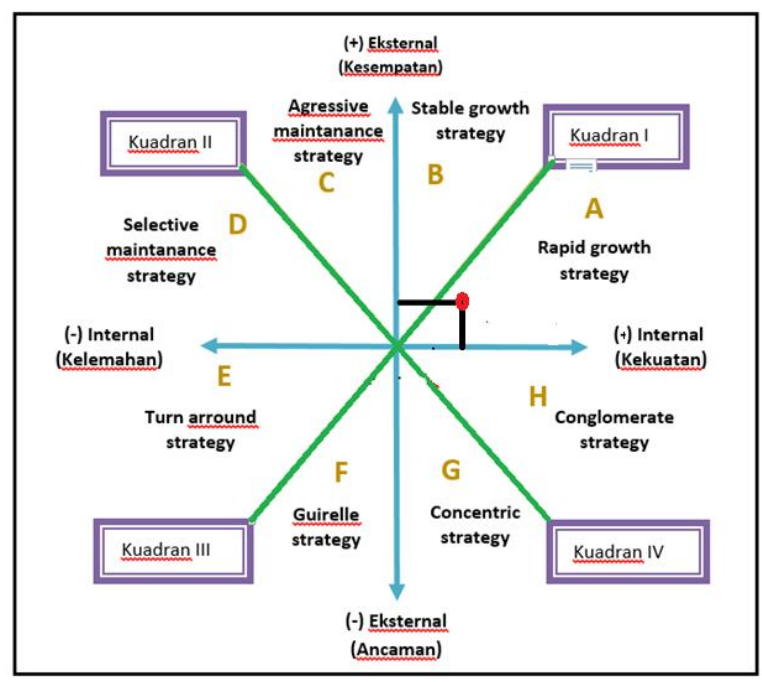

Gambar 5. Kuadran SWOT

Kuadran strategi di atas menunjukkan hasil evaluasi faktor eksternal dan faktor internal dari potensi dan masalah pada evaluasi dan potensi operasional bus sekolah Kota Malang. Berdasarkan grafik tersebut diperolah nilai $\mathrm{X}$ dan nilai Y yang masing-masing mewakili nilai faktor internal dan faktor eksternal. Nilai $X=0,27$ dan untuk nilai $Y=$ 0,2 , apabila ditarik garis lurus antara kedua titik, 
maka titik terdapat pada kuadran I dengan ruang A yaitu rapid growth strategy yakni strategi perumbuhan cepat.

Artinya strategi pengembangan kekuatan dan peluang yang ada dengan cara :

- Mempertahankan kualitas bus sekolah

- Mempertahankan kenyamanan bus sekolah dengan adanya wifi dan AC

- Mempertahankan keamanan bus sekolah

- Mempertahankan subsidi yang diberikan pemerintah

- Memperhatikan ketepatan waktu keberangkatan dan pulang sekolah

\section{KESIMPULAN DAN SARAN}

\section{Kesimpulan}

Kesimpulan dari hasil analisis yang dilakukan untuk melakukan evaluasi dan potensi pengoperasian bus sekolah dengan menggunakan 384 sampel pengguna bus sekolah didapatkan hasil bahwa:

- Kinerja bus sekolah di Kota Malang salah satunya dapat dilihat dari nilai load factor diatas 0,5 yang bisa dikategorikan baik dan kurang dari 0,5 yang belum bisa dikatakan baik. Nilai dibawah 0,5 secara umum berada pada segmen 1 di tiap rute. Hal ini perlu diperhatikan karena nilai load factor yang sangat kecil sehingga membuat segmen pada rute tersebut dirasa kurang efektif untuk perjalanan bus sekolah.Untuk kecepatan perjalanan adalah 40 $\mathrm{km} / \mathrm{jam}$ dengan waktu tempuh 40-60 menit . Waktu pelayanan bus sekolah adalah pagi dan siang hari pada saat berangkat dan pulang sekolah dengan waktu tunggu penumpang antara 5-10 menit. Sementara itu dari hasil perhitungan BOK, ditemukan hasil bahwa 1 bus sekolah membutuhkan biaya sebesar Rp 145.579,- per hari dengan biaya disubsidi oleh pemerintah Kota Malang.

- Secara umum potesi bus sekolah di Kota Malang meliputi keamanan,kenyamanan, ketepatan waktu dan hematnya biaya bagi pelajar yang menaiki kendaraan tersebut. Sementara itu masalah yang ada meliputi kurangnya rute, kapasitas tempat duduk, serta permasalahan dengan pengemudi angkutan umum. Berdasarkan hasil perhitungan analisis SWOT, operasional bus sekolah di Kota
Malang terdapat pada kuadran I yang merupakan kuadran ofensif yakni kuadran yang mendukung strategi dengan ruang A yaitu rapid growth strategy yakni strategi pertumbuhan cepat dengan cara memanfaatkan kekuatan dan peluang yang ada dengan cara mempertahankan kualitas, keamanan, kenyamanan bus sekolah; mempertahankan subsidi yang diberikan pemerinah serta memperhatikan ketepatan waktu keberangkatan dan kepulangan sekolah.

\section{Saran}

Untuk memperbaiki pelayanan bus sekolah di Kota Malang harus dilakukan dengan cepat dan tepat . Beberapa saran yang dapat dilakukan antara lain:

- Perlunya adanya upaya pengembangan pelayanan sesuai potensi dan masalah yang ada, diantaranya adalah :

- Mempertahankan kualitas bus sekolah

- Mempertahankan kenyamanan bus sekolah dengan adanya wifi dan $\mathrm{AC}$

- Mempertahankan keamanan bus sekolah

- Mempertahankan subsidi yang diberikan pemerintah untuk biaya operasional bus sekolah

- Memperhatikan ketepatan waktu keberangkatan dan pulang sekolah

- Dengan kinerja bus sekolah yang sudah baik, diperlukan adanya pengawasan dari pemerintah sehingga bus sekolah tetap berkelanjutan.

- Masih sedikitnya pelajar yang menggunakan bus sekolah dilihat dari nilai load factor, sehingga perlu adanya program sosialisasi pemerintah kepada masyarakat dan pelajar agar animo pelajar untuk menaiki bus sekolah semakin tinggi. Perlu adanya koordinasi dengan pengemudi angkutan umum agar tidak terjadi konflik baik dalam pembagian rute dan jam operasinal bus sekolah.

\section{DAfTAR PUSTAKA}

Agung. 2014. Sistem Angkutan Massal Solusi Atasi Kemacetan. Universitas Gajah Mada. Online : http://ugm.ac.id/. Diakses tanggal 29 November 2014. 
Ali , Muhammad. 1985. Penelitian Pendidikan Prosedur dan Strategi. Bandung. Aksara.

Departemen Pekerjaan Umum. Pedoman Konstruksi dan Bangunan: Perhitungan Biaya Operasi Kendaraan

Departement Perhubungan RI. 2002. Keputusan Direktur Jendral Perhubungan Darat Nomor SK.687/AJ.206/DRDJ/2002 tentang Pedoman Teknis Penyelenggaraan Angkutan Penumpang Umum di Wilayah Perkotaan dalam Trayek Tetap dan Teratur. Direktorat Jendral Perhubungan Darat.

Fatimah, Nur. 2013. Penelitian Deskriptif. Online: http://Penelitian\%20Deskriptif files/ Penelitian\%20Deskriptif.html. Diakses tanggal 22 Februari 2015

Habibi, Yasin. 2015. Ini Rute Bis Sekolah Kota Malang. Republika Online. Online : m.republika.co.id/ Diakses tanggal 11 April 2015

Harries. 1976. Kriteria Angkutan Umum Ideal. ITB

Kevin P. Kearns (Fall 1992)"From Comparative Advantage to Damage Control: Clarifying Strategic Issues Using SWOT Analysis," Nonprofit Management and Leadership, Vol. 3, No. 1. New York: Henry HoltUniversity Koentjaraningrat. 1980. Beberapa Pokok Antropologi Sosial. Jakarta: Djambatan

Kotler, Philip et al. 1993. Manajemen Pemasaran Analisis, Perencanaan, Implementasi dan Pengendalian. Jakarta: Universitas Indonesia Pemerintah Kota Malang. 2010. Profil Kota Malang. Malang

Rahman, Rahmatang. 2012. Analisis Biaya Operasional Kendaraan (BOK) Angkutan Umum Antar Kota Dalam Propinsi Rute Palu-Poso. Jurnal Rekayasa dan Manajemen Transportasi Volume II No.1

Soekanto, Soerjono. 1982. Sosiologi Suatu Pengantar. Jakarta : CV Rajawali

Sudiono, Aries. 2015. Bus Halokes Kota Malang, Dirindukan Pelajar dan. Suara Pembaruan. Online : http://sp.beritasatu.com// Diakses tanggal 11 April 2015

Tamin, O.Z. 1997. Perencanaan dan Pemodelan Transportasi. Bandung: ITB.

Undang-undang No 22 Tahun 2009 tentang Lalu Lintas dan Angkutan Jalan., 